УДК 004.056.53

\title{
АНАЛИЗ СПОСОБОВ ПОВЫШЕНИЯ УРОВНЯ СЕТЕВОЙ БЕЗОПАСНОСТИ БЕСПИЛОТНЫХ ЛЕТАТЕЛЬНЫХ АППАРАТОВ (БПЛА)
}

Зайчиков Илья Дмитриевич Калинина Валентина Александровна студенты Научный руководитель: Галимов Ринат Равилевич доцент кафедры ВТиЗИ ФГБОУ ВО «Оренбургский государственный университет»

Аннотация: в данной статье рассматриваются вопросы защиты беспилотного летательного аппарата и как следствие повышения уровня его безопасности. В работе приведены различные методы противодействия атакам на дроны. Также даны рекомендации по организации защиты БПЛА для общего, профессионального и специального пользования.

Ключевые слова: БПЛА, шифрование, анализ, угрозы, методы мониторинга.

\section{ANALYSIS OF WAYS TO IMPROVE THE LEVEL OF NETWORK SECURITY OF UNMANNED AERIAL VEHICLES (UAVS)}

\section{Galimov Rinat Ravilevich Zaychikov Ilya Dmitrievich} Kalinina Valentina Aleksandrovna

\begin{abstract}
: this article discusses the issues of protecting an unmanned aerial vehicle and, as a result, increasing its safety level. The paper presents various methods of countering attacks on drones. Recommendations on the organization of UAV protection for general, professional and special use are also given.
\end{abstract}

Key words: UAVs, encryption, analysis, threats, monitoring methods.

Всемирное распространение БПЛА позволило их внедрить во многие сферы профессиональной деятельности, такие как сбор географических и 148 
геологических данных в отдалённых местностях, перевоз малогабаритных грузов, съёмка фильмов, телерепортажей и так далее. С увеличением количества информации, обрабатываемой беспилотниками, изменилась категория информации. Всё чаще дроны участвуют в обеспечении защиты крупных предприятий, совершая облёт территорий, где могут пройти нарушители. С развитием технологий злоумышленники научились обходить данную защиту, чаще всего совершая атака на дроны, что приводит к большим потерям. В связи с этим анализ способов защиты беспилотных летательных устройств от реализации угрозы является достаточно актуальным для рассмотрения.

Целью данной работы является разработка рекомендации по использованию методов повышения уровня надёжности БПЛА.

Для достижения данной цели были решены следующие задачи:

- произведён поиск методов защиты БПЛА;

- осуществлён анализ перечисленных методов;

- на основе анализа составлена рекомендация по применениям методов.

Главная уязвимость БПЛА является соединение между пультом управления (ПУ) и беспилотником. Реализация угрозы может произойти от случайно, из-за таких вещей как большое количество открытых Wi-fi точек, плохие погодные условия и другое. Снизить риски можно, изменив динамический МAC-адрес на статический. Так беспилотник будет привязан к одной сети и не будет пытаться подключиться к другой сети. Для надёжности стоит установить пароль на изменение настроек и добавить в память два-три MAC-адреса, чтобы была возможность сменить при необходимости пульт управления.

Внедрение в ПО дополнительных средств мониторинга, таких как перекрёстная проверка инерциального измерительного устройства (IMU), поляризационная проверку; проверка угла прихода сигнала; криптографическая аутентификация [1, с. 860-863] увеличит вероятность выявления нарушений в работе системы.

В случаях открытых соединений БПЛА и ПУ предотвратить атаку можно путём оперативного обнаружения. В работе [2, с. 116-126] представлен метод определения атаки при помощи проведения анализа потока команд. Данный способ найдёт несоответствие подаваемых команд с выполняемыми, что будет свидетельствовать о попытке провести взлом. 
В работе [3, с. 33-41] показан способ определения нападения с помощью анализа сетевого трафика, передаваемого между БПЛА и ПУ. Изменение размеров файлов, протоколов, времени передачи демонстрирует наличие злоумышленника в сети.

В качестве комплексной защиты может выступать внедрение дополнительного программного обеспечения, таких как Protected Access. Программы такого типа помимо проверок, создают канал соединения, по которому всё проходит по единому зашифрованному протоколу.

Активно развиваются методы по ответной атаке нарушителям. Одним из таким средств, является алгоритм, описанный в работе [4, с. 134-137]. Принцип прост: сетевая карта дрона переводится в режим мониторинга и производит сканирование сети, после выявления возможных противников производится подавления с помощью специальной программы.

Рекомендуемый метод защиты является шифрование. В первую очередь стоит зашифровывать GPS-канала, по которому передаются координаты. Это обезопасит от попытки узнать данные о местности и от атаки по замене координаты точки возврата.

Для зашифровки канала связи необходимо использовать методы, основанные на шифрах, которые легко внедрить в программную систему беспилотника и которые при работе будут задействовать меньше ресурсов процессора. Одним из таких методов является перестановочное декодирование, представленное в работе [5, с. 41-47]. Его применение позволяет на коротком отрезке времени выполнить маскировку реальной структуры сигнала.

Оптимальным и простым способом защиты является метод на основе шифрования данных с ключом [6, с. 10-12]. Использование данного способа позволяет обеспечить эффективную защиты при минимальных ресурсах.

Защита данных на основе шифра Вернама проста в реализации, имеет высокую скорость шифрования, а также малую нагрузку на процессор.

При анализе, представленных методов защиты БПЛА, были выявлены ряд достоинств и недостатков (табл. 1). 
Таблица 1

\section{Способы повышения зашишённости БПЛА}

\begin{tabular}{|c|c|c|}
\hline Описание & Достоинства & Недостатки \\
\hline Методы мониторинга & $\begin{array}{l}\text { Просто внедрить в программный } \\
\text { комплекс беспилотника }\end{array}$ & $\begin{array}{l}\text { Возможны сбои в работе } \\
\text { при неправильной } \\
\text { установке или после } \\
\text { проведения калибровки }\end{array}$ \\
\hline $\begin{array}{l}\text { Шифрование GPS- } \\
\text { канала }\end{array}$ & $\begin{array}{l}\text { Надёжная защита от смены GPS } \\
\text { данных }\end{array}$ & $\begin{array}{l}\text { Нет эффективного метода } \\
\text { шифрования, сам канал } \\
\text { остаётся открытым }\end{array}$ \\
\hline $\begin{array}{l}\text { Установка } \\
\text { дополнительного ПО }\end{array}$ & $\begin{array}{l}\text { Комплексный способ защиты: } \\
\text { осуществление мониторинга и } \\
\text { шифрование данных }\end{array}$ & $\begin{array}{l}\text { Затрагивает большой } \\
\text { объём памяти, способ } \\
\text { шифрования на основе } \\
\text { протокола WAP, который } \\
\text { можно взломать }\end{array}$ \\
\hline Анализ команд & $\begin{array}{l}\text { Оперативное выявление } \\
\text { несанкционированных действий }\end{array}$ & $\begin{array}{l}\text { Применим только тогда, } \\
\text { когда известен полёт } \\
\text { маршрута беспилотника }\end{array}$ \\
\hline Анализ трафика & Быстро определяет сетевую атаку & $\begin{array}{l}\text { Не эффективен при атаке } \\
\text { с подменой сетевого } \\
\text { трафика }\end{array}$ \\
\hline $\begin{array}{l}\text { Шифрование с } \\
\text { ключом }\end{array}$ & $\begin{array}{l}\text { Обеспечивает надёжный уровень } \\
\text { защиты }\end{array}$ & $\begin{array}{l}\text { Проблема передачи ключа } \\
\text { собеседнику, } \\
\text { невозможность точно } \\
\text { определить автора } \\
\text { сообщения }\end{array}$ \\
\hline Шифрование блочное & $\begin{array}{l}\text { Высокая скорость, малая нагрузка } \\
\text { на процессор, надёжный уровень } \\
\text { защиты }\end{array}$ & $\begin{array}{l}\text { Трудность внедрения в } \\
\text { ПО дрона }\end{array}$ \\
\hline $\begin{array}{l}\text { Установка } \\
\text { статических МАС- } \\
\text { адресов и добавление } \\
\text { базы данных «белых» } \\
\text { МАС-адресов }\end{array}$ & $\begin{array}{l}\text { Эффективная защита от смены ПУ, } \\
\text { возможность быстро восстановить } \\
\text { соединение после потери сигнала }\end{array}$ & $\begin{array}{l}\text { Канал связи остаётся не } \\
\text { зашифрован, данные } \\
\text { пользователя возможно } \\
\text { украсть }\end{array}$ \\
\hline $\begin{array}{l}\text { Ответная атака } \\
\text { (проведение } \\
\text { сканирование } \\
\text { территорий и } \\
\text { отключение дронов } \\
\text { злоумышленников) }\end{array}$ & Эффективное предотвращение атак & $\begin{array}{l}\text { Канал связи не защищён и } \\
\text { может прослушиваться }\end{array}$ \\
\hline
\end{tabular}




\section{Рекомендация по организации защиты БПЛА общего пользования.}

Под общим пользование понимается использование БПЛА в личных интересах без цели получить коммерческую выгоду. Например, съёмки семейного отдыха или поход с друзьями. В данном случае эффективнее и выгоднее использовать следующие решения:

- установка статических МАС-адресов и добавление базы данных «белых» МАС-адресов;

- методы мониторинга

- шифрование GPS-канала.

Представленные средства эффективно использовать как по отдельности, так в комплексе.

Предложенные средства были выбраны, так как, используемые в личных целях БПЛА, не содержат информации, из которой злоумышленники могут извлечь коммерческую выгоду. Для нарушителей выгоднее похитить сам беспилотника, от данной угрозы и защищают рекомендованные методы. Помимо этого, они имеют низкую стоимость, снижают вероятность реализации случайных угроз и обеспечивают надёжный уровень соединения.

Рекомендация по организации защиты БПЛА профессионального пользования.

Под профессиональным пользованием понимается применение БПЛА в профессиональной среде с целью упрощения или ускорения процессов работы. Например, съёмки репортажа, съёмка недвижимости, съёмка местности для составления карты, наблюдение за природой и много другое.

В данном случае эффективнее и выгоднее использовать следующие решения:

- Установка дополнительного ПО

- Шифрование с ключом

Предложенные средства были выбраны, так как БПЛА данного типа обрабатывает большой объёмом данных, которые могут быть интересны нарушителям с коммерческой точки зрения.

В случае облёта БПЛА по назначенной траектории эффективно использовать анализ команд, так как это позволяет обеспечить оперативное обнаружение попытки внедрения и изменения настроек беспилотника.

В случае использовании БПЛА на территории с большим количеством открытых Wi-fi-точек надёжнее использовать анализ трафика, так как это 
позволяет обеспечивают надёжную защиту от возможных сетевых помех и перегрузки сетевого трафика.

Для обеспечения достаточного уровня защиты эффективно использовать рассматриваемые средства в комбинации со средствами для БПЛА общего пользования.

\section{Рекомендация по организации защиты БПЛА специального назначения.}

Под специальным назначением понимается БПЛА предназначенные для выполнения задач в определённой сфере. Например, сельскохозяйственные дроны, военные беспилотники, дроны доставки и другое.

В данном случае эффективнее и выгоднее использовать следующие решения:

- Методы мониторинга

- Шифрование GPS-канала

- Шифрование блочное

- Ответная атака (проведение сканирование территорий и отключение дронов злоумышленников)

Предложенные средства были выбраны, так как БПЛА специального назначения содержит в себе информацию конфиденциального характера, в случае утери, искажении или похищении данной информации, организации, владеющей дроном, грозит большой ущерб.

Таким образом, в результате проведения анализа способов повышения надёжности сетевого соединения между ПУ и БПЛА, были выявлены достоинства и недостатки существующих методов. Из предложенных вариантов защиты составлены рекомендации по обеспечению защиты БПЛА в соответствии со сферами применения и выполнению задач.

\section{Список литературы}

1. Кондрякова, М.А. Уязвимость каналов связи БПЛА / М.А. Кондрякова // Аллея науки. - 2018. - Т. 5. - № 4(20). - С. 860-863.

2. Галимов, Р.Р. Разработка системы обнаружения аномального сетевого потока управления БПЛА на основе сигнатурно-ассоциативного подхода / Р.Р. Галимов, А.Л. Дудко // Теоретический и практический потенциал современной науки : Сборник научных статей. - Москва : Издательство "Перо", 2020. - C. 116-126. 


\section{РАЗВИТИЕ СОВРЕМЕННОЙ МОЛОДЕЖНОЙ НАУКИ: ОПЫТ ТЕОРЕТИЧЕСКОГО И ЭМПИРИЧЕСКОГО АНАЛИЗА}

3. Коннов, А.Д. Разработка метода обнаружения атак на беспилотный летательный аппарат на основе анализа сетевого трафика / А.Д. Коннов, Р.Р. Галимов // Современная наука: актуальные проблемы, достижения и инновации : материалы Международной научно-практической конференции, Чистополь, 29 мая 2020 года / ЧУДПО «Научно-исследовательский и образовательный центр». - Казань: ООО ПК «Астор и Я», 2020. - С. 33-41.

4. Славнов, В.К. Устройство выявления, подавления каналов управления и телеметрии сверхмалых БЛА / В.К. Славнов, О.М. Барсуков, Н.А. Корчагин // Актуальные проблемы деятельности подразделений УИС : Сборник материалов Всероссийской научно-практической конференции, Воронеж, 25 октября 2018 года / Ответственный за выпуск Д.Г. Зыбин. - Воронеж: Издательскополиграфический центр "Научная книга", 2018. - С. 134-137.

5. Сорокин, И.А. Применение метода перестановочного декодирования в системе управления БПЛА малого класса (дроны, мультикоптеры) / И.А. Сорокин, П.Н. Романов, М.Ю. Шибаева // Т-Comm: Телекоммуникации и транспорт. - 2019. - Т. 13. - № 4. - C. 41-47. - DOI 10.24411/2072-8735-201810260.

6. Долгий, Е.Ю. Разработка схемы защищенного канала дальнего радиуса действия для наземной станции управления беспилотного летательного аппарата / Е.Ю. Долгий, К.В. Шошина, Р.А. Алешко. - Текст : непосредственный // Молодой ученый. — 2015. — № 13.1 (93.1). — С. 10-12. URL: https://moluch.ru/archive/93/20826/ (дата обращения: 6.06.2021).

7. Селихов, В.А. Обеспечение безопасности полетов БПЛА / В.А. Селихов // Синергия Наук. - 2018. - № 22. - С. 830-836.

8. Довгаль, В.А. Анализ уязвимостей и угроз безопасности роя дронов с поддержкой Wi-Fi, противостоящего атакам злоумышленников / В.А. Довгаль, Д.В. Довгаль // Вестник Адыгейского государственного университета. Серия 4: Естественно-математические и технические науки. - 2020. - № 3(266). C. 67-73.

9. Авдонин, И.А. Организация защиты данных, передаваемых между беспилотным летательным аппаратом и наземной станцией управления, на основе шифра Вернама / И.А. Авдонин, М.Б. Будько, В.А. Грозов // Научнотехнический вестник информационных технологий, механики и оптики. -2016. - T. 16. - № 5. - C. 850-855. - DOI 10.17586/2226-1494-2016-16-5-850-855. 